\title{
The political economy of technical fixes: the (mis)alignment of clean fossil and political regimes
}

Accepted for publication in Energy Research \& Social Science

Nils Markusson ${ }^{\mathrm{a}^{*}}$, Mads Dahl Gjefsen ${ }^{\mathrm{b}}$, Jennie C. Stephens ${ }^{c}$ and David Tyfield ${ }^{\mathrm{d}}$

a Lancaster University, Lancaster Environment Centre, Lancaster LA1 4YQ, UK.

n.markusson@lancaster.ac.uk

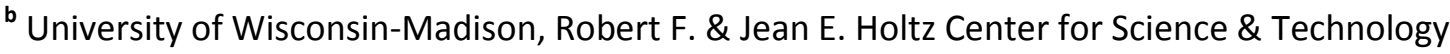

Studies, 1180 Observatory Drive, Madison, WI 53706, USA. madsdg@cantab.net

'University of Vermont, 81 Carrigan Drive, Burlington, VT 05405 USA. jennie.stephens@uvm.edu

' Lancaster University, Lancaster Environment Centre, Lancaster LA1 4YQ, UK.

d.tyfield@lancaster.ac.uk

${ }^{*}$ Corresponding Author

\section{Abstract}

This paper argues that existing critiques of technical fixes are unable to explain our simultaneous enamourment and distrust with technical fixes, and that to do so, we need a political economy analysis. We develop a critical, theoretically grounded conceptualisation of technical fixes as imagined defensive spatio-temporal fixes of specific political economic regimes, and apply it to the case of geoengineering, or 'clean fossil', as an attempted technical fix of the climate change problem. We map the promises of clean fossil as proposed solutions to the problem of climate change in discrete episodes since the 1960s.

The paper shows that clean fossil promises have been surprisingly poorly aligned with the neoliberal regime, and explains how they have been moderately stable due to those misalignments. We also show that different liberal capitalisms could be supported by different clean fossil technologies, but also that illiberal or more egalitarian regimes remain possible alongside particular, perhaps radically re-envisioned, versions of clean fossil. Ambivalence towards clean fossil technical fix promises is intelligible, given the inherent instability of their co-evolution with neoliberalism and future political regimes.

Keywords: neoliberalism, carbon capture and storage (CCS), geoengineering, climate engineering 


\section{Introduction}

Technical fixes imply a use of 'the power of technology to solve problems that are nontechnical in nature' [1 p. 21]. This framing goes back to the mid-1960s, when Alvin M. Weinberg, physicist, made the case for technology's potential to offer cheap and effective solutions to problems ranging from population growth, poverty, energy needs, and water shortages [2]. Citing the difficulty of solving problems by influencing people's motivations and behaviour, Weinberg described technical fixes as 'cheap ... shortcuts' [2 p. 141] 'that are within the grasp of modern technology, and which would either eliminate the original social problem without requiring a change in the individual's social attitudes, or would so alter the problem as to make its resolution more feasible' [2 p. 9].

Weinberg's optimism about technical fixes was criticized even by contemporaries [3, 4], and the term is rarely used with positive connotations today. Instead, technical fix has become a dismissive label for quick and cheap fixes that are 'partial, ineffective, unsuccessful, threatening, one-sided as opposed to holistic, mechanical as opposed to ecological' [3 p.3]. The phrase seems to indicate an improper problem bounding, where 'what is addressed is not the real problem but the problem in as far as it is amenable to technical solutions' [5 p. 152].

In public debates over science and technology, the 'technical fix criticism' is a rhetorical tactic in its own right [6]. For example, in the world of information and communication technology, 'technical fix' has become a stock accusation levied against product demonstrations where efficiency is only proved to the spectator by using a 'technology design framing that constructs organizational practices too narrowly' [7 p. 472]. This usage suggests that the limitations of technological naivety are obvious, and that public awareness of the political character of technology is well-established. Yet, an enamourment-distrust paradox remains. Despite consistent expressions of disillusionment, the popularity of promised technical fixes continues to demonstrate society's focus on technology when solving problems $[3,6,8]$, and a sustained ambivalence about technical fixes.

We argue here that the existing literature on technical fixes is unable to explain satisfactorily this paradoxical resilience of technical fixes, and especially so in circumstances where fixes are seen to be both problematic in practical terms and normatively contested. To explain this, we need an analytical framework capable of analysing what technical fixes do, practically, culturally and politically, as both promises and implemented systems. Specifically, the framework needs to be capable of explaining which fixes are supported, what interests they defend, and when they might work or fail. For this purpose, we develop a cultural political economy of science and technology framework drawing on Tyfield $[9,10]$, and apply it to the empirical case of geoengineering as a technical fix to the climate change problem.

Climate change first emerged as a policy concern in the 1960s, soon followed by proposals for engineering solutions that would allow us to preserve our fossil fuel-based society [11, 12, 13, 14]. Since then, geoengineering, or 'clean fossil', in various forms has remained a part of climate policy. In the 1960s and 1970s, two technical approaches were discussed: (1) changing the reflectivity of the planet (today referred to as solar radiation management, SRM), and (2) sequestering $\mathrm{CO}_{2}$ (currently referred to as carbon dioxide removal, $\mathrm{CDR}$ ). From the 1990s, capture of $\mathrm{CO}_{2}$ from large point sources - especially fossil fuelled power plants - and subsequent sequestration in geological formations (carbon dioxide capture and storage, CCS) was the most prominent technical fix promise. 
In the last 15 years, the term geoengineering, defined to include all clean fossil apart from CCS, has been used to frame a revived interest in several other geoengineering technologies, cf. Figure 1.

We include geoengineering technologies in the category of 'clean fossil' because the promise of geoengineering is precisely to come to the rescue when fossil fuel based emissions prove hard to avoid. Notable exclusions from the category include renewables, which are disruptive to fossil fuel use, and more efficient power plants, which are merely incrementally cleaner than existing technology.

Whilst there have been research and a few demonstration projects for some technology variants (including several CCS demonstration plants), overall clean fossil remains unimplemented. There is, however, a range of active technology specific research and development communities [15, 16, 17], with varying levels of industry and state involvement, and actors who are interested in geoengineering as a whole. While the communities around CCS and geoengineering are distinct, some actors (including researchers like ourselves) have overlapping interest in both areas [18, 19, 20, 21].

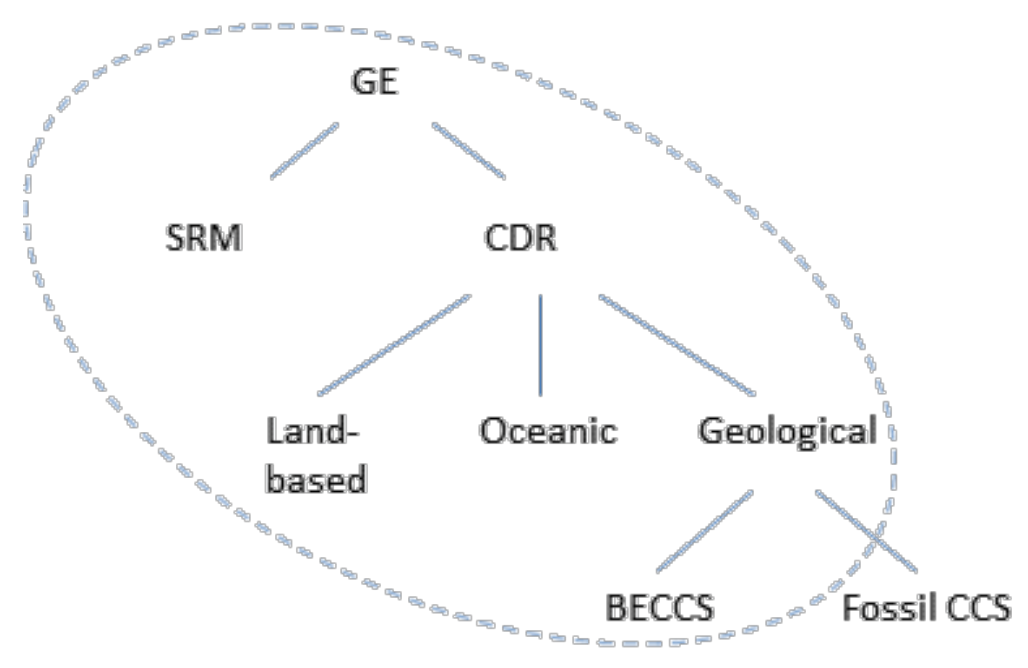

Figure 1. The different categories of clean fossil technology. The dashed line signifies geoengineering (GE). BECCS = CCS on bioenergy fuelled power plant.

Geoengineering is a technical fix par excellence, calling on technological solutions to complex (socioenvironmental) problems on an unprecedented, planetary scale in ways that would profoundly - and deliberately - redefine our relationship with, and position in, the Earth system as one of human technological mastery [22, 23]. Clean fossil technologies have been analysed (and critiqued) as a technical fix before. For example, Sarewitz and Nelson [24] argue that air capture technology is a better technical fix than CCS, for a set of practical reasons. Scott [25] argues that geoengineering as a technical fix is ethically problematic, in terms of who gets to set criteria for success, and for reinforcing a norm that humans should dominate nature. Corner and Pidgeon [26] warn that geoengineering as a potentially quick and cheap technical fix has the potential to mobilise economic 
and ideological interests, and so distract from more expensive mitigation. However, none of these authors analyses the political economy of clean fossil in any detail.

Clean fossil illustrates the role technical fixes play in the evolution of political regimes. Tyfield [10] has shown how coal-dominated CCS technology (and our continued underlying reliance on coal, notwithstanding recent bankruptcies and turmoil in the coal industry $[27,28]$ ) fits badly with the oilbased [29] neoliberal regime, even as it appears, prima facie, to align perfectly. It promises to clean up fossil based society whilst leaving our lifestyles and production systems more or less intact, and it promises to do so mediated by neoliberal policy based on emissions markets that match emissions with sinks (or warming with cooling) at the lowest possible cost. Yet, paradoxically, CCS continues to struggle, with just one plant attached to fossil-fuelled electricity generation currently in operation, out of approximately 1500 plants that the International Energy Agency estimates are needed; and with that one also facing significant difficulties [30].

Neoliberalism is here defined as the unlimited faith in the capacity of markets to solve the problems involved in governing human affairs [31]. This means that within neoliberalism there is no way of conceiving of existential threats that are unamenable to market-based solutions. Carbon trading can handle climate change only if it is seen not as an irreducible and existential 'threat' that simply must be avoided as a whole, but as a phenomenon that is at least sufficiently malleable and amenable to market-based socio-technical intervention as to be manageable (i.e. optimizable) on that basis, i.e. as being merely a 'risk' [31]. Risks are calculable, manageable by markets and so 'knowable' (i.e. by what the market subsequently makes manifest as the case) under neoliberalism. But threats cannot be thus mitigated and are not calculable and manageable by markets. Instead threats require limits set to the freedom of markets on the basis of other, non-market knowledgeable judgements and executed by non-market forces, notably government. CCS implementation requires long-term planning of infrastructure and investments in large demonstration plants without hope of short-term profit - a poor fit with the incremental, nimble, short-term (and financialized) investments favoured by markets. CCS might therefore do better under other political regimes that are better equipped to deal with existential threats through forms of state planning.

This paper extends Tyfield's analysis of CCS to all of clean fossil. Whilst clean fossil was first conceived during the peak of the social liberal political regime in the 1960s (what Jessop [32] defines as the Keynesian national welfare-warfare state regime), it was after the breakthrough of neoliberal [31] policy making in the 1980s and the later formulation of early climate policies that the promise of clean fossil, then in the form of CCS, became prominent in the 1990s. Mounting environmental and financial challenges to neoliberalism over the last decade has coincided with growing interest in geoengineering. Malm [33] argues that in an economy based on and committed to production and consumption of fossil fuels, and where current political regimes are neither channelling enough capital to renewables nor willing to phase out fossil fuel use, we are faced with a choice of planning either the climate or the economy. Geoengineering thus promises to defend fossil interests, including many of the world's largest companies and the wider fossil fuel dominated economy. Geoengineering has therefore been attractive also to former climate sceptics and a range of conservative lobbyists otherwise unsupportive of energy system changes [34].

Geoengineering is in important ways even more attractive as a specifically neoliberal technical fix than CCS. Where CCS entails a material flow of $\mathrm{CO}_{2}$ from power producer to storage operation, 
geoengineering's connection between $\mathrm{CO}_{2}$ source and sink is a book-keeping construct with unlimited scope for financialized marketization of the atmosphere, flexibility for polluters, and avoidance of state planning [35]. Geoengineering seems to be the acme of neoliberal fossil clean-up policy [31]. In addition, the existence of a small set of offsetting-orientated CDR projects, using mainly ocean iron fertilisation $[36,37]$ but also $\operatorname{BECCS}[38,39,40]$, suggests a potential for entrepreneurship and innovation. But we will show that geoengineering has, for similar and different reasons to CCS, fitted poorly with neoliberalism. Crucially, the paper also extends Tyfield's analysis by focussing on promises of technical fixes. For both CCS and geoengineering, we analyse promises and material implementation, and how they fit with political regimes, separately. This allows us to discern the political role of promises as such, and to analyse how combinations of promise and (non-)implementation co-evolve with political regimes.

This paper thus asks how clean fossil as a fix for anthropogenic climate change, and as both promise and implementation, has co-evolved since the 1960s with the political regimes that have dominated the global system (including technological innovation). What expectations about the relation between government and markets have been articulated together with clean fossil promises, and what power relations have they therefore promised to defend, challenge, construct or destroy? Conversely, what effects have these promises of technical fixing had as regards those apparent goals? Finally, what indications do we have concerning the possible future pathways for the coevolution of clean fossil and political regimes? In our response to these questions, we provide a novel, theoretically grounded characterization of technical fixes, and of their central, if contested, role in contemporary society. Finally, we discuss how the co-evolution of clean fossil technical fix promises and political regimes makes ambivalence intelligible, and thus helps explain the enamourment-distrust paradox.

\section{Registers of Promotion and Critique of Technical Fixes}

This section reviews the key literature on technical fixes. Whereas previous critiques of the concept are unable to explain the technical fix enamourment-distrust paradox, we argue that a political economy approach can substantially illuminate this tension.

Scott $[6,25]$ argues that criticisms of technical fixes broadly fall into two categories. On the one hand, there are 'pragmatic' [25] (or 'practical' [6]) criticisms concerning the effectiveness of technical fixes, and on the other there are 'philosophical' criticisms of technical fix framings as manifestations of a technocratic culture that avoids challenging established power relations. Pragmatic criticisms operate on the same register as Weinberg's original promotion of technical fixes, but argue that they fail, not succeed, on this basis.

A fine-grained characterisation of technical fixes on the pragmatic register is provided by LeCain's [41] classification of fixes that either transform key components of a problem (e.g. by turning a pollutant into a commodity), relocate problem components (from a context where they cause harm), or delay negative effects. While each of these outcomes can be considered successes when evaluated against narrow problem framings, they may also produce unintended side effects while conserving the systems and practices that were the underlying source of undesirable outcomes [6 p. 216]. 
Discussions on the pragmatic register suggest that technical fixes recur because they are perceived to often work and that side-effects can be mitigated against with improved technical knowledge about wider system contexts. Contemporary defenders of technological fixes have shown sensitivity to pragmatic criticisms [42]. In an attempt to promote effective and reflexive use of technical fixes in policy contexts, Sarewitz and Nelson [24] propose that technical fixes are most appropriate when focussing on a clearly defined cause-effect relationship within an otherwise complex problem context, have verifiable and uncontested effects within that context, and consist of technologies that embody an established, technical knowledge core - as opposed to depending on the creation of new fundamental knowledge (see also [43]). For them, the success of technical fixes hinges on isolatable problem contexts. Their recommendations echo Hughes' defining distinction between "partial, reductionist" technical fixes, and systemic solutions that more fully acknowledge "the complexity of the problem to be solved" [44 p. 241, 243].

Discussions of technical fixes on the pragmatic register thus indicate that there is scope (under particular circumstances) for using technology to solve, if imperfectly, social problems. The enamourment-distrust paradox is here merely the contrast between enthusiasm over what works, and disappointment with unforeseen side-effects. But, crucially, this argument does not help explain the recurrence of technical fixes as solutions also for contested problems, where there is no consensus regarding what works, what the salient problem context is, or what drives the scientificpolitical work needed to produce consensus and construct an isolatable problem context in the first place [45]. Therefore, we need to move beyond the pragmatic register.

Scott's second category concerns so-called philosophical criticisms, exemplified with reference to among others Lynn White [46] and Alan Drengson [47]. Scott also cites Leo Marx [48], who saw technological fixes as rooted in uncritical beliefs in technological progress as the primary measure of societal reform, one so embedded in our culture that it shapes our very conception of history. For Scott, philosophical criticisms portray technical fixes as emerging from 'basic assumptions' in our civilisation's view of progress and commitment to instrumentalism. This rendering would suggest that the enamourment-distrust paradox can be seen not just as a result of pragmatic, rationalist assessments of what works (and what doesn't), but also a commitment to the symbolic values of 'T'echnology (and critiques of it).

Discussion on the philosophical register usefully draws our attention to the fact that technical fixes have significance not just as implemented socio-technical systems, but also as a pattern of thought. We would add that the mere making of promises of future technical fixes has impacts, of both practical and political kinds. This stance resonates with recent science and technology studies scholarship on technological promises and sociotechnical imaginaries-or "collectively imagined forms of social ... order" [49 p. 120] reflected in states' justifications for large-scale technology projects. Science and technology studies has also taught us about experts' role(s) in closing down and depoliticising promises of science and technology [50]. Understanding the dynamics of promisemaking has direct relevance for on-going efforts to open up expert framings and facilitate extended, plural debates that re-politicise innovation processes [51]. Notable recent contributions to these efforts include the rapidly growing literature on anticipatory governance [52] and responsible research and innovation [53]. This literature suggests that the whole concept of a lasting 'fixed' solution is problematic and instead the 'solution' is progressively shifting to a process of re- 
politicised contestation about innovation, leading to more profound changes in society, not just technology band-aids on given social structures.

But why do technical fix promises often persist in the face of sustained contestation by plural voices? And, more generally, why has the mode of technical fix thinking been so resistant in spite of the development of a seeming 'common sense' that gives the very term a negative ring? The philosophical critique goes some way to explain this. Drengson [47] warned that the deeply rooted technocratic and instrumentalist worldview reifies power relations, and that it underlies technical fixes that seek to address specific problems without challenging reigning paradigms. Dominant power regimes play a key role here: in the context of climate change, for instance, Hamilton [54] claims that focusing on technical fixes allows us to avoid uncomfortable conclusions about the need to challenge entrenched patterns of power and consumption. Criticisms on the philosophical register thus suggest that technical fix promises have a defensive element to them, that they conserve inplace power structures and discredit or distract attention away from measures that might weaken the systemic foundations of dominant regimes, and this fact matters for the resilience of technical fix thinking. Technical fixes will thus tend to appear exactly where there is contestation. On this register, the enamourment-distrust paradox becomes an interplay between the technical fix promises from powerful, but blinkered, elites (and their experts) and the usually, but not always, suppressed insights from and resistance of marginalised (lay) people.

Whilst the philosophical critique suggests that the recurrence of technical fix promises is related to dominant power regimes, it leaves the specifics of this interaction un-scrutinised. The philosophical critique does not explain which specific technical fixes are supported, what exactly they defend, and under what particular circumstances that support or defence will work or fail. For example, what particular interests have the clean fossil promise functioned to serve, and how has it done so? And how should we understand the ebb and flow of support for specific clean fossil technologies?

Nor does the philosophical critique say much about how new political regimes could emerge, in coevolution with technical fixes. Whilst it seems entirely plausible that the promise of clean fossil fits well with the current neoliberal political regime, can we see, in the misalignments between the two that are also evident, seeds of different - worse or better - future regimes? Technical fix promises cannot be dismissed as merely defensive, as per the philosophical critique, but can also be seen to signal hope, even if it is seemingly against the odds.

A general reference to defence of, and resistance against, current power regimes is thus not a sufficient explanation of the enamourment-distrust paradox; we need to provide an analysis of what fixes work, when, and why that is both substantive and historically situated. For this, we need to add a political economy register to the literature that affords a co-evolutionary analysis of the political, institutional and material mechanisms that mediate technical fixes: both as a form of (loosely conceptualised) societal thinking style, as per the philosophical register, and in ways that serve to defend specific, current power relations, but in contingent, imperfect ways, thereby allowing also for (conceptualization of) change to both political regime and technical fixes. On such a political economy register, both enamourment and distrust can then be seen as reasonable attitudes to have towards the co-evolution of technical fixes and political regimes, if not necessarily in equal measures at any given point in time. 


\section{A Cultural Political Economy Perspective on Technical Fixes}

We here develop a framework for analysing what technical fixes do, as promises and as realised socio-technical systems, and how historically contingent forms co-evolve with (dominant) political economic regimes.

We take as our starting point a model of the co-evolutionary link between technology and political regimes under liberal capitalism, where we assume that promises of new technology have generative potential insofar as they are used to legitimate (arrow 1 in Figure 2) new spatio-temporal fixes ${ }^{1}$, i.e. new contingent opportunities for capital, which defer its tendency to crisis, whilst shifting problems to other places or times [55]. Clean fossil can usefully be seen as a spatio-temporal fix. It would offer opportunities for investment, and so potentially be a response to not only the ongoing climate crisis, but also the financial one. Many CDR type technologies would require vast amounts of land, displacing other uses and livelihoods and so constitute a spatial fix, whereas especially SRM type technologies risk postponing warming problems into the future as a temporal fix [56].

\section{Co-evolution of technologies and political regimes}
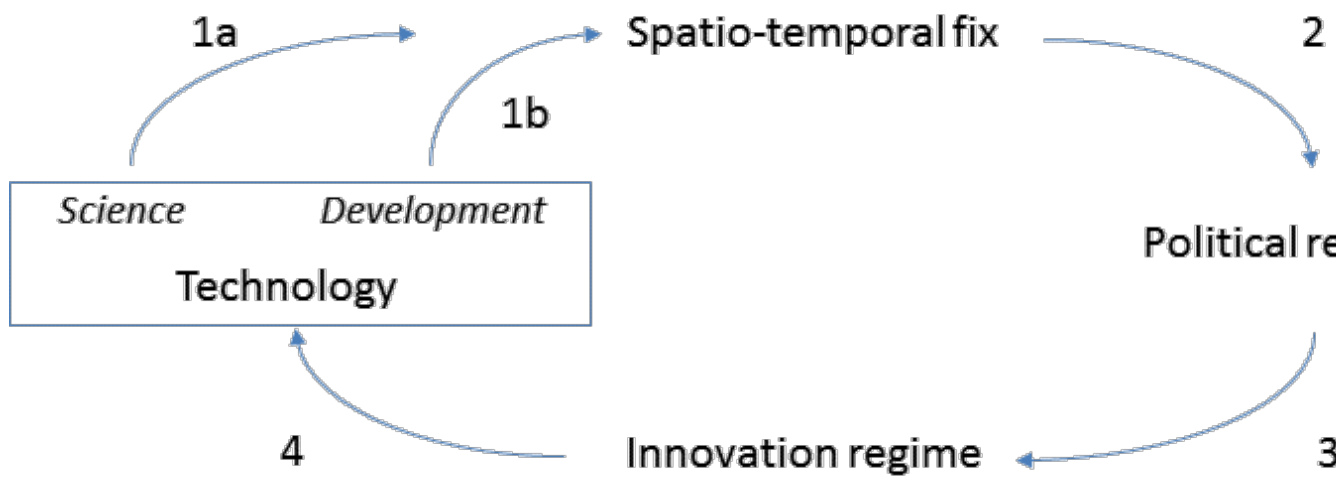

\section{Political regime}

Innovation regime

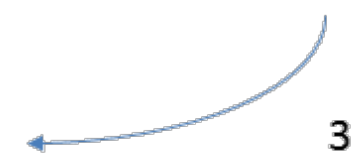

Figure 2. Co-evolution of technologies and political regimes.

Spatio-temporal fixes, in turn, legitimise and enable specific political regimes (arrow 2). By political regime we here mean both a specific set of actors that dominate society economically and politically, but crucially also a set of institutions embodying their hegemonic ideals and rationality. Whilst liberalism has been the underlying regime under capitalism, a more fine-grained periodisation is possible, with distinctly different political regimes - most lately neoliberalism, and before that social-liberalism. The political regime tends to favour particular kinds of innovation regimes (arrow 3 ), i.e. sets of rules and norms for what kinds of innovation to support [57]. Innovation regimes thus support and enable the development of specific technologies (arrow 4).

\footnotetext{
${ }^{1}$ Not to be confused with technical fixes. Explanation follows below.
} 
Whilst there can be positive feedback loops in the model leading to periods of relative stability, there is also constant change at each point in the model. And, equally crucial, each step of this cycle is mediated and manifest only in concrete actions, so that such positive feedback loops are not an inherent part of this model in the abstract, but a specific achievement of ongoing effort and practice in the form of mutual strategic alignment. Constant recalibration and realignment is going on, and at times the system transitions to new political regimes.

The capitalist imperative to innovate is an important driver of this dynamic, and science an increasingly important source of novelty. Under the current neoliberal regime, the ideal innovation is one that promises quick economic returns, as well as private control of technology and resources. A key role of the state is to create new markets for such technologies, legitimised as solutions to common problems. In contrast, under the post-war social liberal innovation regime, the role of the market was circumscribed by state regulation, and the state took on responsibility for some kinds of innovation and ownership of certain operations $[29,58]$.

'Technology' is here shorthand for both scientific knowledge production and the development of socio-technical systems. Science is a rich source of promises (arrow 1a in Figure 2) of new STFs, creating rhetorical spaces for them, and development realises (arrow $1 \mathrm{~b}$ ) these promises as material, socio-technical systems. The model thus captures the prospective rhetorical use of promises to legitimise action in the now, and specifically to create new spaces, and define new kinds of objects that can be developed and invested in. It also indicates how technological promises, alongside development of material socio-technical systems, are crucial for the evolution of capital and political regimes.

We are here interested in technical fixes, as a special category of technologies. On our political economy register, a technical fix promise is an attempt to legitimise, with reference to an important problem, a spatio-temporal fix that can shore up a particular, current (more or less problematic) political regime. Such a technical fix may or may not work practically and/or politically, and may produce unexpected outcomes in the longer run. For example, the case for clean fossil is as a response to climate change which clearly qualifies as a collectively recognised problem, and is dependent on the technology leaving hard-to-reform fossil-fuel-based value chains including consumer behaviours untouched, with the promise of doing so in a way that is compatible with neoliberal market-based climate policies, and hence defending the socio-political status quo.

While technological promises potentially assist and legitimise the setting up of new STFs, and thence the evolution of capitalism from one dominant regime to another, they need not, however, do this or successfully achieve this. These promises can also be connected with the system-defensive and conservative role of technical fixes. When, for example, CCS technology promises to legitimise a new use of (and investment in) the underground for the purposes of waste storage, this does open up a new space for capitalist expansion. But the main attractiveness of the idea is its promise to conserve previous investments and so maintain rather than supplant earlier STFs. We thus need to define as a special category defensive STFs that serve to support other already-existing STFs.

Finally, no promises can determine eventual spatio-temporal fix outcomes, which rather are brought about through an unfolding, contingent innovation process, with an inherent capacity for surprises. Part of the reason for this is that no articulation of a promise is ever completely monovalent, but rather multiple, and so comes with built-in alternative outcomes. But crises and surprises are also an 
inherent potential of a distributed process involving multiple actors with some autonomy and agency. Any attempt to pin down and fix a problem tends to be imperfect, and problems tend to overflow the bounds set up for it, creating new problems [35]. We thus also need to be aware of the capacity of promises, contingently, to lead to STFs other than those expected when taken at face value. And so political regimes are not just forever re-produced through technical fixes, but can also evolve through them. Technical fixes can thus also contribute to regime shifts.

With this elaboration, we have a model of the co-evolution of technical fixes and political regimes. Within this model, promises of technical fixes legitimise, and actual manifestation of technical fixes sediments, defensive spatio-temporal fixes. Both types of fix, therefore, serve to ' $\mathrm{fix}$ ', patch or manage the ongoing emergence of ruptures at system level that are an inescapable feature of an expanding capitalist political economy, with the technical fix a special subset of the broader category of spatio-temporal fixes. What is crucial, however, is that the promise and actual delivery of a technical fix must be analytically distinguished and their effects explored separately.

This paper will apply this elaboration of technical fixes to the case of clean fossil, and we will use this model to guide our investigation into the co-evolution of clean fossil promises and political regimes.

\section{Methodology}

The paper aims to use the case of co-evolution of clean fossil promises and political regimes to 1) investigate what is defended by technical fix promises and when such promises work or fail, and 2) identify the conditions that make technical fix ambivalence intelligible.

To meet the first aim, we need to document and map clean fossil promises from their emergence in the 1960s, to today. We identify and describe episodes of politically relevant (re)articulations [47] of clean fossil technology. We are interested in clean fossil not just in terms of narrowly technical function but also in terms of its implied social function [38 p.124]. We also add a specific focus on the irreducibly capitalist political-economic character of the dominant regimes, unlike in previous historical accounts of clean fossil $[11,12]$. Specifically, we analyse the explicit or implied role of states and markets in the visions for clean fossil articulated by prominent organisations, e.g.

Intergovernmental Panel on Climate Change (IPCC) and governments. We are especially interested in what role, if any, the state has in the articulation - as regulator or owner in social liberal articulations, or as market creator in neoliberal ones. We focus on dominating, prominent articulations and attempt no exhaustive mapping, whilst also acknowledging that there are significant ambiguities and diversities regarding the role of the state articulated in the episodes.

Based on this mapping, we are then able to analyse the co-evolution of clean fossil promises as technical fixes and the political regime. We identify alignments and misalignments between clean fossil promises and the neoliberal regime, and use them to explain the stability of the neoliberal regime, and the stability and change of clean fossil promises.

To meet the second aim, we also explore how the political regime may co-evolve with stable or changing clean fossil promises in the future. The retrospective and prospective analyses together help us illustrate the indeterminate and unpredictable nature of such co-evolution. We may then show how, even in the face of an entrenched pattern of clean fossil promises supporting a seemingly 
stable neoliberal regime, we can still reasonably expect the evolution of different political futures, in co-evolution with new and old clean fossil type technical fix promises, to be possible. Ambivalence towards technical fixes is thus an intelligible attitude in the case of clean fossil.

Finally, we will be able to generalise from the clean fossil case, and draw conclusions about the (political economic) nature of technical fixes, and explain their paradoxical resilience.

\section{Results}

This section describes six significant re-articulation episodes that together provide the contours of a shift from social liberal to neoliberal articulations of clean fossil, and perhaps beyond.

\section{Episode 1: Clean fossil initially proposed in a social liberal context}

In the mid-1960s, the US government funded an environmental research report [59], the first government statement on both global warming and clean fossil $[11,12,13,14]$. The report presents clean fossil as a potential response to anthropogenic climate change, in the context of a social liberal articulation of the problem.

The report's recommendations state that " $\mathrm{t}] \mathrm{h}$ he possibilities of deliberately bringing about countervailing climatic changes therefore need to be thoroughly explored" [59 p. 127], and highlights two albedo changing (i.e. SRM type) technologies: spraying particles over large ocean surfaces, and injecting condensation (and freezing) nuclei into high cirrus clouds. The report does not discuss $\mathrm{CO}_{2}$ sequestration, or removal of $\mathrm{CO}_{2}$ from flue gases. These notions and the term geoengineering itself were introduced by Marchetti [60] more than a decade later.

The report articulates a tension between the need to allow industrial consumer society to continue and a need for government intervention to protect citizens and future generations. Regulation is the main approach discussed for dealing with pollution. The report does mention the need to look into the scope for "tax-like ... effluent charges" [59 p. 17], prefiguring a later shift to neoliberal articulations and emissions trading as a preferred policy.

The report does not propose climate change policy beyond research funding, and even in terms of research, clean fossil wasn't to become a vigorous area of research and debate until the 1990s (in the form of CCS), cf. [15] and Figure 3. The report does provide an indication of early social liberal articulation and as such a baseline against which we can contrast later neoliberal articulations. 


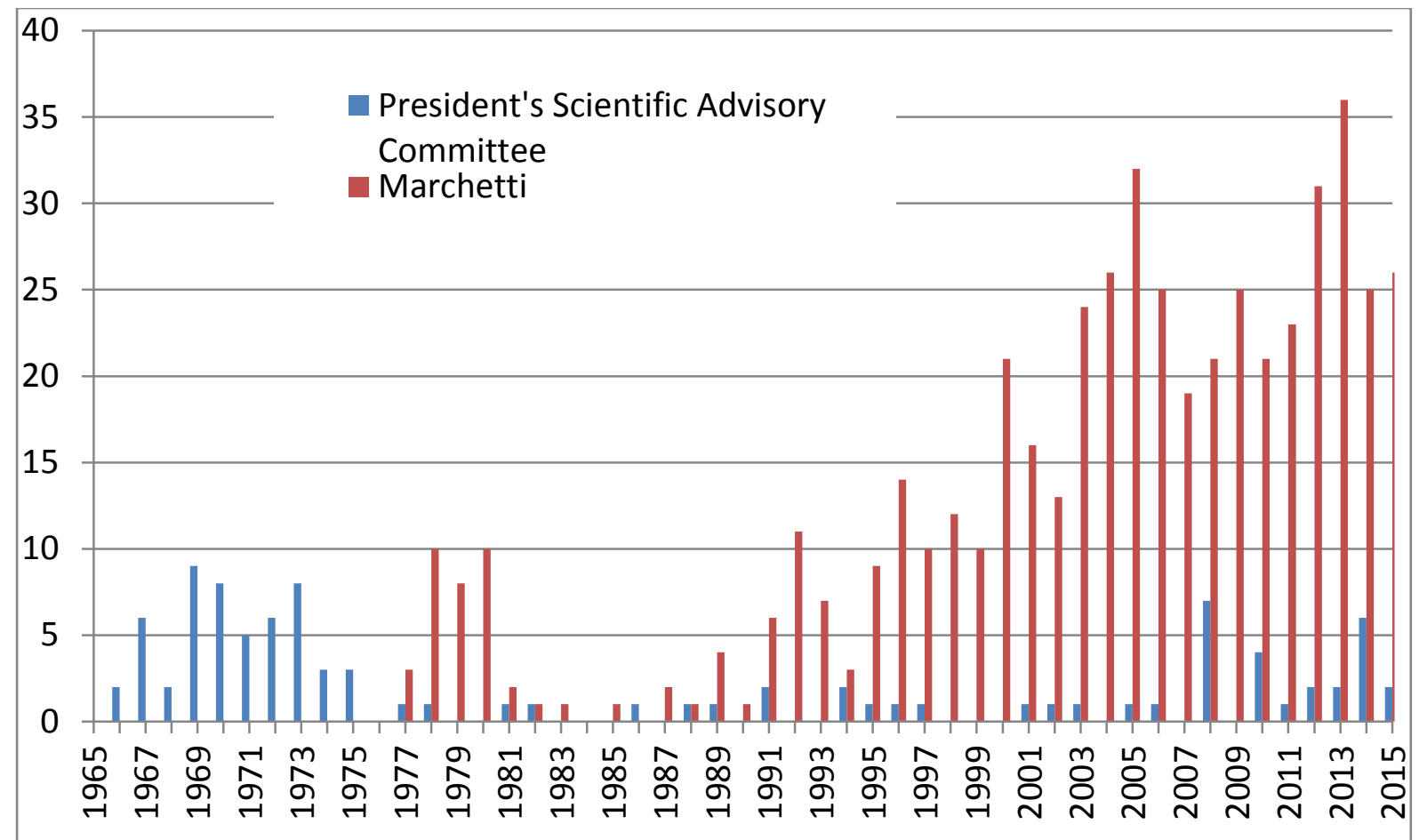

Figure 3. Number of citations of the President's Scientific Advisory Committee report of 1965 [59] and Marchetti's 1977 paper [60]

Note: Data from Google Scholar, produced using Publish or Perish software, downloaded Feb. 2016.

The rise and fall of neoliberally articulated CCS technology

The 1980s saw the breakthrough of neoliberalism and the birth of neoliberal climate policy with emphasis on carbon price as the prime mover $[61,62]$. Amongst clean fossil technologies, especially interest in CCS grew from the mid-1980s, and it was articulated neoliberally from the start. Indeed, the technology has played a key part in reconciling fossil fuel interests (and climate scepticism) with the climate change imperative under the neoliberal regime.

\section{Episode 2: Early articulation}

In 1991, Norway became one of the first countries to introduce a carbon tax. The tax was intended not only as a climate change mitigation measure, but also as a way to unleash the technological potential of CCS, applied to $\mathrm{CO}_{2}$ from offshore gas turbines. To evade the tax, the Norwegian petroleum company Statoil launched the Sleipner $\mathrm{CO}_{2}$ storage project in 1996 [63, 64] . Sleipner became the world's first large-scale geological $\mathrm{CO}_{2}$ storage operation [64].

The most expensive part of CCS involves separating $\mathrm{CO}_{2}$ from flue gases from fossil fuelled energy production. The Sleipner project instead used already separated $\mathrm{CO}_{2}$ from natural gas processing, and so capture from flue gases remained un-demonstrated at large scale. In this sense the tax failed to stimulate CCS fully. The project has often been invoked by scientists to emphasize the security of 
geological storage of $\mathrm{CO}_{2}[65,66]$, but it was also an early demonstration of the failure of the neoliberal regime to provide a sufficient carbon price to drive CCS implementation.

\section{Episode 3: The apex}

Neoliberal belief in carbon trading, and its ability to help deliver CCS implementation, remained strong. In 2005, the IPCC, the key body synthesizing international climate change science for policymakers, published a special report on CCS [67], providing critical legitimacy and evidence for its technical feasibility [68].

The IPCC report advocates carbon trading as a policy to drive investment, but also recognises the high price tag of CCS. To bridge the financial gap between the high costs of CCS development and the near-term financial benefits of implementing the technology, the report advocates public-private partnerships and government investment in demonstration projects. The intention was to reduce costs [68] and enable later carbon market-driven deployment.

The IPCC special report was intended to break a deadlock in international climate policy by proposing a technical solution that would not alienate fossil fuel interests, and bring countries including the US on board [69]. Government investment in CCS promised a fix of neoliberal climate policy, and the IPCC report legitimized that promise.

\section{Episode 4: Giving up?}

This optimism was followed by very slow progress for CCS demonstration, as well as international climate policy generally. Carbon prices remained low or absent, and few CCS projects materialised [70]. The neoliberal articulation of CCS faltered.

CCS advocates in the US began emphasising $\mathrm{CO}_{2}$ utilisation as a pathway to CCS development after the 2009 failure of key legislation that could have sparked a carbon trading system. Utilization includes Enhanced Oil Recovery (EOR) using captured $\mathrm{CO}_{2}$, a practice largely at odds with climate mitigation. US CCS advocates promoted the acronym 'CCUS' (Carbon Capture Utilization and Storage) to emphasise the commercial viability of CCS-related technologies applied primarily to EOR [71]. The CCUS re-articulation was an attempt to maintain momentum with the hope that technology development spill over back to CCS [72]. The US government took several steps to support this reframing, and CCUS became established as the official US policy lingo in CCS-related efforts. In 2012, the Department of Energy renamed its annual meeting on CCS the 'Annual Carbon Capture, Utilization and Sequestration Conference', while the US-led, ministerial-level international Carbon Sequestration Leadership Forum instituted a $\mathrm{CO}_{2}$ utilisation taskforce [73], spreading the term to other countries.

EOR could become a neoliberal clean fossil promise. Monitoring, measurement and verification of injected $\mathrm{CO}_{2}$ could incorporate EOR operations into emissions markets mechanisms. But, crucially, the CCUS re-articulation did not hinge on emissions markets to support EOR. Rather, it was the hope 
of revenue from EOR to help finance development of capture technology that drove this development.

CCUS signified a deferral of the neoliberal CCS promise, in favour of spontaneous market dynamics (akin to classical liberalism). The promise of CCS to reconcile fossil interests and the climate imperative was stretched close to its breaking point. CCUS was also not a wholesale deferral of the neoliberal CCS promise, as it has lived on in for example IPCC reports [74]. Rather, we have seen a diversification of articulations of CCS. Also, CCS has been boosted by recent attention to BECCS as a carbon sink technology.

\section{The political ambivalence of recent geoengineering promises}

The articulation of CCS with the neoliberal regime worked well as a promise of a technical fix to climate change, but remained unimplemented. In contrast, more recent geoengineering initiatives have had an even more troubled relationship with the neoliberal regime, as not even their promises have been well aligned.

\section{Episode 5: Promotion and warnings}

Geoengineering research grew rapidly in the early 2000s [15], and in 2009, a report from the UK Royal Society consolidated and legitimised (in science policy if not immediately in climate policy) this renewed interest [75]. The report classifies geoengineering technologies into two categories: CDR and SRM, with the emphasis on the primarily technical difference between radiation and sequestration.

The report devotes significant attention to geoengineering's risks and uncertainties of geoengineering. Its governance recommendations include calls for regulation of both research [76], and deployment [75]. The state is assigned responsibility for making geoengineering happen, using the familiar neoliberal carbon price, established through taxes or emissions trading. The report is distinctly ambivalent about geoengineering entrepreneurship, both lauding private entrepreneurship's ability to mobilise resources and accelerate development, and expressing concern that "commercial involvement could bypass or neglect the socio-economic, environmental and regulatory dimensions" [75 p. 44]. Overall, the report has elements of neoliberal policies of market creation, but also a strong social liberal regulatory role for government.

\section{Episode 6: A partial resolution}

This ambivalence was carried through to the 2014 IPCC $5^{\text {th }}$ Assessment Report [74], the first IPCC report to include a comprehensive review of geoengineering [77], which consolidated an uptake of the idea in climate policy related discourse. The report partly resolves the political ambivalence, by treating CDR and SRM separately and very differently. 
CDR - and especially BECCS [74 p. 23] - is included in climate scenarios. The report states that BECCS is likely required to avoid warming above 2 degrees, and that any delays in emissions reduction will increase our need for CDRs [74]. SRM technology is excluded from the scenarios because it "entail[s] numerous uncertainties, side effects, risks and shortcomings, and has particular governance and ethical implications" [74 p. 26]. SRM raises serious issues of how to ensure "legitimate decision making, monitoring and control" [78 p. 488]. There is no suggestion that markets can provide such legitimacy, and responsibility for decision-making is assigned to states.

Overall, there are plenty of caveats to the report's commitment to neoliberal market creation, with strong limitations placed on not only what is possible but also legitimate concerning SRM. The report presents SRM with such strong concerns that it is a distinct challenge for neoliberal innovation regimes, whereas CDR is compatible.

\section{Discussion}

\subsection{History}

Despite evidence of alignments between the neoliberal political regime and clean fossil technical fix promises, the above episodes do not suggest strong productive feedback loops (cf. Figure 2), but rather obstacles and cracks. From the perspective adopted here, therefore, this suggests significant ruptures and weaknesses at the level of the neoliberal regime itself (and hence its innovation model), since it is unable to implement solutions, or, in the case of geoengineering, (wholly) dominate even the discourse of what should be quintessentially neoliberal technical fix. This, in turn, leads to further pressures on the regime, and contributes to undermining it.

But why then has the CCS technical fix promise remained relatively stable over a period of around 30 years, despite contestation and failure to deliver? The promise of fossil abatement has upheld the climate policy regime and its neoliberal emphasis on emissions trading and offsetting. The CCS promise has helped build political and industrial support for international climate policy, and has been co-constitutive of $\mathrm{CO}_{2}$ emissions trading markets and associated efforts at stabilising and reinvigorating the neoliberal regime. Given the neoliberal innovation regime's inability to produce implementation via competition and markets, continued commitment to the promise of CCS has been necessary, as a response to the misalignments.

It seems a fair hypothesis that BECCS could be the next technical fix promise lined up for this role of discursive stabiliser. And this does not bode well for its development since support by and framing in terms of a neoliberal political regime that is itself in trouble may well be a positive impediment to its success, as it has arguably proven for CCS.

In this analysis, the technical fix promises are defensive precisely as long as they are not acted upon in the sense of technology implementation. This is not an argument about conspiracy and deception (although there may be elements of that), but an analytical observation of the role of the CCS promise, in the context of a dynamic neoliberal innovation regime and ongoing attempts to preserve it, and its oil-based political regime. As promises, the imagined defensive STFs can be used not only to legitimise new STFs, but also to defend existing investments (in previous STFs) even without 
realising the defensive STFs. Cf. arrow 1a in Figure 4. At the very least, their realisation can be deferred for some time without much harming the usefulness of the promise as a defensive move.

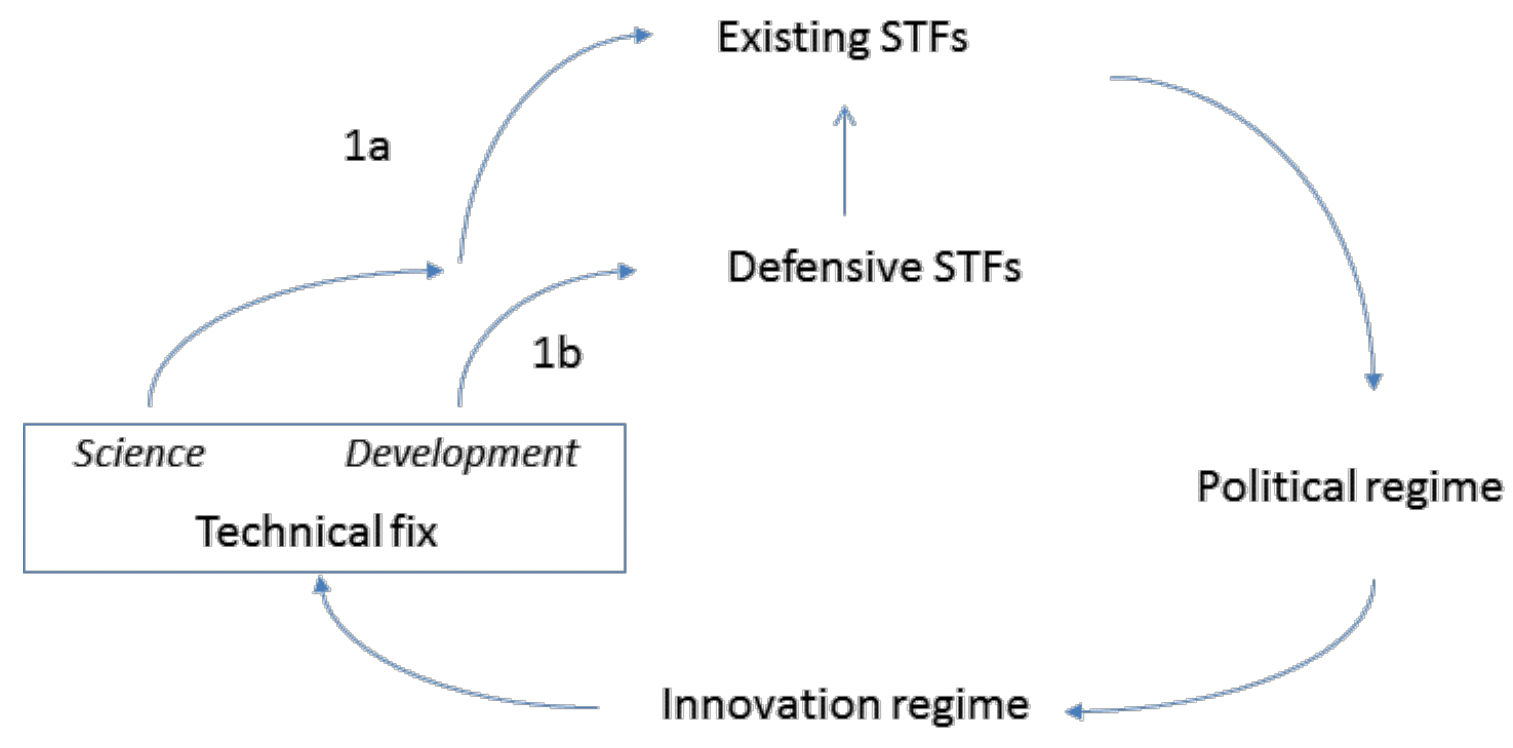

Figure 4. Co-evolution of technical fixes and defensive spatio-temporal fixes.

Moreover, why hasn't geoengineering been unambiguously articulated as a neoliberal technical fix promise? One reason appears to be that geoengineering is a heterogeneous category where some component technologies fit better with emissions trading than others. We can distinguish between what we call 'one-off' and 'modular' geoengineering, which is about how divisible geoengineering technologies are. For example, there are several good reasons for not having multiple stratospheric aerosol injection projects running in parallel. It is potentially a powerful technique, and doing too much of it too quickly (or ceasing too abruptly) can disrupt the climate system. Multiple projects would also make it more difficult to know the effect of each. For these reasons, and others, centralised control has been seen as paramount $[74,75]$. In contrast, with most sequestration techniques modular deployment is unavoidable, and with their much slower impact there is less risk inherent in a decentralised governance system, such as a market. Modular geoengineering technologies are much more promising as neoliberal spatio-temporal fixes than one-off ones.

But then why has the umbrella term of geoengineering survived its misalignment with the neoliberal innovation regime? Whilst some CDR technologies, notably afforestation, already had a foothold in climate policy, SRM technologies didn't and had the most to gain from joint promotion. The dominant definition is symmetrical with respect to CDR and SRM, but much geoengineering debate has tended to be about SRM, or even about stratospheric aerosol injection as the emblematic geoengineering technology. An ambivalent articulation in relation to the neoliberal regime is better for SRM technology proponents than an outright rejection, and so the geoengineering label still has traction amongst them. The label has also resonated quite well amongst detractors, and in the media, which has helped sustain its use. 
The survival of the geoengineering umbrella term may have further explanations. Echoing the above argument about the technical fix promises' defensive function, the discussion of SRM as a highly problematic promise requiring state regulation can be interpreted as a functional threat.

Stratospheric aerosol injection evokes fears of illiberal political regimes [79], reminding us of the militarised cold war context of the idea's initial articulation. The illiberal SRM threat makes CDR and CCS seem reasonable as neoliberal technical fixes, and, by extension, defends the neoliberal regime.

The neoliberal regime hasn't managed even to fully shape the articulation of the geoengineering promise, which evokes social liberal-style concerns about the SRM's impacts and illiberal threats. As a climate change response, geoengineering is more flagrantly limited as neoliberal technical fix promise than is CCS. Moreover, geoengineering offers even shakier support for the neoliberal regime itself. Instead of self-sustaining and dynamic positive feedback loops between technical fix (promise and actuality) and political regimes, we find both parallel processes and relations between them that are weakening and fragmenting.

The misalignments between clean fossil and the neoliberal regime do not spell immediate collapse of the latter. Rather, what we see is a degree of stability whereby the neoliberal regime is defended, at least temporarily, by - on the one hand - retaining the promise whilst deferring deployment (of CCS), and - on the other - shoring up an imperfectly neoliberal promise with threats of illiberal political regimes (of certain types of SRM). While misalignments can be made to work for the current regime, the cracks seem to be widening.

We have seen here how technical fixes can be not only materially defensive (fixing the problem as an end of pipe, add-on solution) but also discursively defensive (greenwash) and that the relation between these two defensive functions is complex. Our analysis goes beyond the philosophical critiques of technical fixes in analysing the specifics of what is being defended, how it is being defended and why this may be effective or not.

\subsection{Futures}

Our analysis breaks with both pragmatic and philosophical critiques of technical fixes. We highlight how technical fix promises not only represent potentially workable solutions, or discursive acts that legitimise spatio-temporal fixes in defence of current power regimes, but that promises also have a more radically generative potential. Currently dominating articulations do not predict the future, which may unfold in surprising ways, but we do see minor alternative articulations as 'seeds' of radical futures that can productively be discussed using our theoretical framework. We now turn, therefore, to exploring how clean fossil may co-evolve with the currently dominant political regime in the future.

Multiple scenarios are possible, supported by varying amounts of evidence. Here we outline four possible scenarios for the future co-evolution of different combinations of political regimes and clean fossil promises and deployments. The scenarios include continued neoliberalism, but also explore a range of - both more and less attractive - alternative political regimes.

\section{Scenario 1}


As a baseline, we can think of continued neoliberal non-implementation of clean fossil. The carbon price signal would remain weak, and current articulations are here quite stable, with little technology deployed beyond CCUS. This is close to business as usual, so there is supporting evidence. But, we also know that the neoliberal regime is under stress [58], partly due to its limited success in shaping technical fixes (and especially ones for global ecological challenges, such as geoengineering) both materially and discursively, while underpinning significant pressures on the climate, and may come to be replaced.

\section{Scenario 2}

Another possibility, perhaps a worst case scenario from a democratic point of view, involves recourse to illiberal SRM (cf. [79]). Here, post-democratic apathy segues into autocracy or oligarchy, where a technocratic elite deploys the technology, maybe justified as a response to climate emergencies. In an Orwellian version of this scenario, the term geoengineering might thrive. The centralising quality of some SRM technologies has reasonably made many observers wary of their democratic consequences, but there is otherwise little evidence for this future unfolding.

\section{Scenario 3}

The antithesis to scenario 2 is a strongly democratic geoengineering, with bottom-up, local engagements with the climate $[80,81]$. This would require a radical re-articulation of both geoengineering and the climate change problem, and a focus on relatively low-tech and small-scale technologies. Martindale [82] analyses Transition Town practices as potential democratic geoengineering, and here we have moved beyond what would currently be labelled technical fixes as such practices are typically not readily quantified and commodified [35]. But beyond these academic exercises, there is little direct evidence for a link being forged between the geoengineering term and grassroots practices, and even these do not seriously discuss how such 'democratic' GE could, and would have to, co-evolve with a change of political regime.

\section{Scenario 4}

An additional scenario is to take the current remaining interest in fossil CCS and the growing interest in some CDRs seriously. This would seem to require a resurgent but still liberal regime with a stronger regulatory intervention and even public ownership of infrastructure. As Tyfield [10] discussed, a scenario of this kind might develop in coal-dependent China with its strong state, although not in a social liberal form but a liberalism 2.0 reminiscent of the $19^{\text {th }}$ century liberalism of coal's initial global ascendancy. This is characterised by the primacy of individualised negative liberty and a continuing privileging of markets, but where markets are nonetheless deposed from their centrality under neoliberalism by a resurgent argument in favour of ('strong') states rectifying market failures. The geoengineering concept might here be abandoned, in favour of CDR.

This systematic speculative analysis of four scenarios shows that our conceptual model can also help us think through the varying political roles and characters of (promises of) technical fixes in potential futures more or less foreshadowed by current articulations. Where promises are discursively defensive, they might nevertheless indicate potentially radical material change in the emerging future. In relation to pragmatic critiques of technical fixes, we have added the insight that technical fixes can prefigure technical (and political) change even when they don't work in practical terms. 
And in relation to the philosophical critique, we have argued that technical fixes may not only be conservative of power regimes but also engender societal change. In short, exploring the coevolution of technical fixes and political regimes affords insights into both, and their inter-relations, which substantially confound the expectations of more familiar forms of critique of technical fixes.

Together, the retrospective and prospective analyses above also show how, even in the face of an entrenched pattern of clean fossil promises supporting a seemingly stable neoliberal regime, we can still reasonably expect the evolution of different political regime futures, better or worse than the current one, to be possible. In this context of inherently unstable co-evolution of clean fossil technical fixes with political regimes, ambivalence about those fixes is readily intelligible. It is reasonable to be simultaneously enamoured and distrustful of clean fossils, though not in some kind of rational balance but as a dynamic and changing judgement regarding the specifics of the technical fix in question and the evolution of its socio-technical trajectory and the political regime it is understood, however inchoately, to be conditioning.

\section{Conclusion}

We have here developed a cultural political economy conceptualisation of technical fixes, as both promises and implemented socio-technical systems, and applied it to the case of clean fossil as a response to climate change. Seeing technical fix promises as attempted defensive justifications of existing and new spatio-temporal fixes allows us to shed new light on the recent co-evolution of clean fossil articulations with political regimes. Moreover, analysis of the dynamic and unruly process of aligning promises of technical fixes and the political regime provides evidence for a systematic speculative analysis about potential future regimes.

The analysis allows us to explain the relative stability of specific technical fix promises in the face of faltering implementation efforts and ongoing contestation. And we are able to re-theorise, beyond established philosophical critique, the general tendency to resort to technical fix promises exactly when they are the both most ineffectual and most contested. Opening up technical promises challenges technocracy, but the political regime can accommodate and thrive off a multiplicity of promises, and use (at least some of) them to sustain itself. But at the same time, the imperfect and never completely stable ways in which the regime and technical fixes are aligned may contain also the seeds of radically new spatio-temporal fixes supporting a different political economy regime.

Defining technical fix promises as attempted justifications of defensive spatio-temporal fixes gives the concept a new theoretical foundation as well as a new critical edge. What is at stake is not just pragmatic, rationalist knowledge claims (cf. pragmatic critique), or culturally embedded technocratic modes of problem-solving and a general technocratic tendency to deflect attention from power relations (cf. philosophical critique), but also the fate of specific (existing and new) spaces for capitalist investment (through markets or the state), and the future specific form of capitalist social relations.

Our analysis also shows that ambivalence towards clean fossil technical fix promises is intelligible, given the inherent instability of their co-evolution with neoliberalism and future political regimes. The balance of enamourment and distrust will vary with the specifics of the historical situation and 
the details of the technical fix proposals being presented. Even so, given capitalism's crisis tendencies, our enamourment with technical fixes is unlikely to be completely replaced by distrust. And so technical fix promises will tend to recur, seemingly paradoxically. Enamourment with technical fixes is not just about whether they work, or whether they defend the establishment, but also about what (however faint) political hope they signal, alongside (commonsensical) distrust and despair.

\section{Table of acronyms}

\begin{tabular}{|l|l|}
\hline BECCS & BioEnergy CCS \\
\hline CCS & Carbon dioxide Capture and Storage \\
\hline CCUS & Carbon dioxide Capture, Utilisation and Storage \\
\hline CDR & Carbon Dioxide Removal \\
\hline EOR & Enhanced Oil Recovery \\
\hline IPCC & Intergovernmental Panel on Climate Change \\
\hline SRM & Solar Radiation Management \\
\hline
\end{tabular}

\section{Acknowledgements}

We'd like to thank the three reviewers for their helpful comments, and Tanya Williamson, Lancaster University Library, for help with citation data

\section{References}

1. Varma, R., Technological fix: Sex determination in India. Bulletin of Science, Technology \& Society, 2002. 22(1): p. 21-30.

2. Weinberg, A.M., Reflections on Big Science. 1967, Cambridge, MA: MIT Press.

3. Rosner, L., The technological fix: how people use technology to create and solve problems. 2004: Routledge.

4. Gibbons, M., Scientists and Society. Nature, 1970. 228(October 24, 1970): p. 387.

5. Van den Hoven, J., G.J. Lokhorst, and I. Van de Poel, Engineering and the problem of moral overload. Science and engineering ethics, 2012. 18(1): p. 143-155.

6. Scott, D., The technological fix criticisms and the agricultural biotechnology debate. Journal of Agricultural and Environmental Ethics, 2011. 24(3): p. 207-226.

7. Smith, W., Theatre of Use: A Frame Analysis of Information Technology Demonstrations. Social Studies of Science, 2009. 39(3): p. 449-480.

8. Gibbons, M., The CERN $300 \mathrm{GeV}$ accelerator: a case study in the application of the Weinberg criteria. Minerva, 1970. 8: p. 180-191.

9. Tyfield, D., The Economics of Science: A Critical Realist Overview. Volume 2: Towards a synthesis of political economy and science and technology studies. . 2012, London \& New York: Routledge.

10. Tyfield, D., King Coal is Dead! Long Live the King!: The Paradoxes of Coal's Resurgence in the Emergence of Global Low-Carbon Societies. Theory, Culture, and Society, 2014. 31(5): p. 5981.

11. Keith, D., Geoengineering the Climate: History and Prospect. Annual Review of Energy and the Environment, 2000. 25: p. 245-284. 
12. Fleming, J., Fixing the Sky: The checkered history of weather and climate control. 2010, New York: Columbia University Press.

13. Oldfield, J., Climate modification and climate change debates among Soviet physical geographers, 1940s-1960s. WIREs Climate Change, 2013. 4: p. 513-524.

14. Bonnheim, N.B., History of Climate Engineering. WIREs Climate Change, 2010. 1: p. 891-897.

15. Belter, C. and D. Seidel, A bibliometric analysis of climate engineering research. WIRES Climate Change, 2013. 4(5): p. 417-427.

16. Oldham, P., et al., Mapping the landscape of climate engineering. Philosophical Transactions of the Royal Society A: Mathematical, Physical and Engineering Sciences, 2014. 372(2031).

17. Stephens, J.C., et al., Characterizing the International Carbon Capture and Storage Community. Global Environmental Change, 2011. 21: p. 379-390.

18. Markusson, N., et al., Contrasting medium and genre on Wikipedia to open up the dominating definition and classification of geoengineering. Big Data \&amp; Society, 2016. 3(2).

19. Markusson, N., A. Ishii, and J.C. Stephens, The Social and Political Complexities of Learning in CCS Demonstration Projects. Global Environmental Change 2011 21: p. 293-302.

20. Stephens, J.C. and S. Jiusto, Assessing innovation in emerging energy technologies: Sociotechnical dynamics of carbon capture and storage (CCS) and enhanced geothermal systems (EGS) in the USA. Energy Policy, 2010. 38 p. 2020-2031.

21. Gjefsen, M.D., Carfting the expert-advocate: Training and recruitment efforts in the carbon dioxide capture and storage community. Innovation: The European Journal of Social Science Research, 2016.

22. Wibeck, V., A. Hansson, and J. Anshelm, Questioning the technological fix to climate change - Lay sense-making of geoengineering in Sweden. Energy Research \& Social Science, 2015. 7: p. 23-30.

23. Galarraga, M. and B. Szerszynski, Making climates: solar radiation management and the ethics of fabrication, in Engineering the Climate: The Ethics of Solar Radiation Management, , L. Christopher Preston, MD: , Editor. 2012, Lexington Books. p. pp. 221-235.

24. Sarewitz, D. and R. Nelson, Three rules for technological fixes. Nature, 2008. 456(7224): p. 871-872.

25. Scott, D., Geoengineering and Environmental Ethics. Nature Education Knowledge, 2012. 3(10): p. 10.

26. Corner, A. and N. Pidgeon, Geoengineering the climate: the social and ethical implications. . Environment: Science and Policy for Sustainable Development, 2010. 52(1): p. 24-37.

27. Macalister, T., World's Largest coal Producer Files for Bankruptcy Protection, in The Guardian. 2016: London.

28. Carbon Tracker, The US Coal Crash, Evidence for Structural Change. 2015:

http://www.carbontracker.org/wp-content/uploads/2015/03/US-coal-designed-Web.pdf.

29. Mitchell, T., Carbon Democracy, Political Power in the Age of Oil. 2011, London and New York: Verso.

30. Austen, I., Technology to Make Clean Energy from Coal is Stumbling in Practice, in New York Times. 2016: New York.

31. Mirowski, P., Never let a serious crisis go to waste: How neoliberalism survived the financial meltdown. 2013: Verso.

32. Jessop, B., Liberalism, Neoliberalism, and Urban Governance: A State-Theoretical Perspective. Antipode, 2002. 34(3): p. 452-472.

33. Malm, A., Socialism or Barbeque, War Communism or Geo-Engineering: Some Thoughts on Choices in a Time of Emergency., in The politics of ecosocialism: Transforming welfare, $\mathrm{K}$. Borgnäs, et al., Editors. 2015, Routledge: London. p. 180-194. 
34. Sikka, T., A critical discourse analysis of geoengineering advocacy. Critical discourse studies, 2012. 9(2): p. 163-172.

35. Lohmann, L., Marketing and making carbon dumps: commodification, calculation and counterfactuals in climate change mitigation. Science as Culture, 2005. 14(3): p. 203-235.

36. Buesseler, K.O., et al., Ocean Iron Fertilization--Moving Forward in a Sea of Uncertainty. Science, 2008. 319(5860): p. 162.

37. Factor, S., The Experimental Economy of Geoengineering. Journal of Cultural Economy, 2015.

38. Azar, C., et al., The feasibility of low $\mathrm{CO} 2$ concentration targets and the role of bio-energy with carbon capture and storage (BECCS). Climatic Change, 2010. 100: p. 195-202.

39. Vergragt, P.J., N. Markusson, and H. Karlsson, Carbon capture and storage, bio-energy with carbon capture and storage, and the escape from the fossil-fuel lock-in. Global Environmental Change, 2011. 21(2): p. 282-292.

40. Gough, C. and N.E. Vaughan, Synthesising existing knowledge on the feasibility of BECCS. Tyndall Centre for Climate Change Research, 2015.

41. LeCain, T.J., When Everybody Wins Does the Environment Lose? The Environmental TechnoFix in Twentieth-Century American Mining, in The technological fix: how people use technology to create and solve problems, L. Rosner, Editor. 2004, Routledge. p. 137-153.

42. Sarewitz, D., Looking for quality in all the wrong places, or: the technological origins of quality in scientific policy advice, in The politics of scientific advice: Institutional design for quality assurance, J. Lentsch and P. Weingart, Editors. 2011, Cambridge University Press: Cambridge, MA USA. p. 54-70.

43. Almudi, I. and et al, A formal discussion of the Sarewitz-Nelson rules. Economics of Innovation and New Technology, 2016: p. 1-17.

44. Hughes, T., Afterward, in The technological fix: how people use technology to create and solve problems, L. Rosner, Editor. 2004, Routledge. p. 241-243.

45. Latour, B. and S. Woolgar, Laboratory Life: The Social Construction of Scientific Facts. 1979: Princeton University Press.

46. White, L., The historical roots of our ecological crisis. This sacred earth: religion, nature, environment, 1967: p. 184-193.

47. Drengson, A., The sacred and the limits of the technological fix. Zygon, 1984. 19(3): p. 259275.

48. Marx, L., Are Science and Society Going in the Same Direction?. Science, Technology, \& Human Values, 1982. 8(4): p. 6-9.

49. Jasanoff, S. and S.-H. Kim, Containing the atom: Sociotechnical imaginaries and nuclear power in the United States and South Korea. Minerva, 2009. 47(2): p. 119-146.

50. Wynne, B., Misunderstood misunderstanding: Social identities and public uptake of science. Public Understanding of Science, 1992. 1(3): p. 281-304.

51. Stirling, A., Opening up" and "closing down" power, participation, and pluralism in the social appraisal of technology. Science, Technology \& Human Values, 2008. 33(2): p. 262-294.

52. Guston, D.H., Understanding 'anticipatory governance'. Social Studies of Science, 2014. 44(2): p. 218-242.

53. Stilgoe J., W.M., Kuo K. , From Bio to Geo: Implications from public engagement with new technologies for geoengineering research governance. PLos Biology, 2013. 11(11).

54. Hamilton, $\mathrm{C}$., The Clique that is trying to frame the global geoengineering debate. The Guardian, 2011.

55. Harvey, D., The New Imperialism. 2003, Oxford: Oxford University Press.

56. Sapinski, J.P., Climate politics, capitalism, and the governance of solar radiation management, in Third ISA Forum of Sociology. 2016: Universität Wien, Vienna, Austria, 10-14 July.

57. Godoe, H., Innovation regimes, $R \& D$ and radical innovations in telecommunications. Research Policy, 2000. 29: p. 1033-1046. 
58. Tyfield, D., A Cultural Political Economy of Research and Innovation in an Age of Crisis. Minerva, 2012. 50(2): p. 149-167.

59. PSAC, Restoring the Quality of our Environment, Report of the Environmental Pollution Panel. 1965, President's Science Advisory Committee, Washington DC: The White House.:

Washington DC.

60. Marchetti, C., On Geoengineering and the $\mathrm{CO}_{2}$ Problem. Climatic Change, 1977. 1(1): p. 5968.

61. Lohmann, L., Financialization, commodification and carbon: The contradictions of neoliberal climate policy. Socialist Register, 2012. 38: p. 85-107.

62. MacNeil, R. and M. Paterson, Neoliberal climate policy: from market fetishism to the developmental state. Environmental Politics, 2012. 21(2): p. 230-247.

63. Tjernshaugen, A., Gasskraft: Tjue års klimakamp. . 2007, Oslo: Pax Forlag: Oslo, Norway.

64. Statoil, Sleipner West. www.statoil.com/en/TechnologyInnovation/NewEnergy/Co2CaptureStorage/Pages/Sleipner Vest.aspx [Retrieved Feb 19, 2016], 2013.

65. Cavanagh, A.J. and R.S. Haszeldine, The Sleipner storage site: Capillary flow modeling of a layered $\mathrm{CO} 2$ plume requires fractured shale barriers within the Utsira Formation. International Journal of Greenhouse Gas Control, 2014. 21: p. 101-112.

66. Scott, V., North Sea: Carbon dioxide storage is secure. Nature, 2014. 506(7486): p. 34-34.

67. IPCC, IPCC Special Report on Carbon Dioxide Capture and Storage. 2005, Intergovernmental Panel on Climate Change, Working Group III: Geneva.

68. Kheshgi, H., H. de Coninck, and J. Kessels, Carbon dioxide capture and storage: Seven years after the IPCC special report. Mitigation and Adaptation Strategies for Global Change, 2012. 17: p. 563-567.

69. Narita, D., Managing uncertainties: The making of the IPCC's: Special Report on Carbon Dioxide Capture and Storage. Public Understanding of Science, 2010.

70. Scott, V., et al., Last chance for carbon capture and storage. Nature Clim. Change, 2013. 3(2): p. 105-111.

71. Atlantic Council, Issue Brief: US Policy Shift to Carbon Capture, Utilization, and Storage Driven by Carbon Dioxide Enhanced Oil Recovery. 2012, Atlantic Council: Washington DC.

72. Endres, D., et al., Putting the $U$ in carbon capture and storage: rhetorical boundary negotiation within the CCS/CCUS scientific community. Journal of Applied Communication Research, 2016. 44(4): p. 362-380.

73. Gjefsen, M.D., Carbon cultures: Technology Planning for Energy and Climate in the US and EU. Science \& Technology Studies, 2013. 26(3): p. 63-81.

74. IPCC, Climate Change 2014: Synthesis Report. Contribution of Working Groups I, II and III to the Fifth Assessment Report of the Intergovernmental Panel on Climate Change, R.K.P.a.L.A.M.e. Core Writing Team, Editor. 2014, IPCC: Geneva, Switzerland.

75. Royal Society, Geoengineering the climate: science, governance and uncertainty. 2009, The Royal Society: London.

76. Gardiner, Some Early Ethics of Geoengineering the Climate: A Commentary on the Values of the Royal Society Report. Environmental Values, 2011. 20: p. 163-188.

77. Cressey, D., Climate report puts geoengineering in the spotlight. Nature, 2013(http://www.nature.com/news/climate-report-puts-geoengineering-in-the-spotlight1.13871).

78. IPCC, Climate Change 2014 Mitigation of Climate Change. 2014, Intergovernmental Panel on Climate Change. https://www.ipcc.ch/report/ar5/wg3/.

79. Macnaghten, P. and B. Szerszynski, Living the global social experiment: An analysis of public discourse on solar radiation management and its implications for governance. Global Environmental Change, 2013. 23(2): p. 465-474. 
80. Buck, H.J., Geoengineering: Re-making Climate for Profit or Humanitarian Intervention? Development and Change, 2012. 43: p. 253-270.

81. Olson, R.L., Soft Geoengineering: A Gentler Approach to Addressing Climate Change. Environment: Science and Policy for Sustainable Development, 2012. 54(5): p. 29-39.

82. Martindale, L., Understanding humans in the Anthropocene: Finding answers in geoengineering and Transition Towns. Environment and Planning D, 2015. 33(5): p. 907-924.

83. Stilgoe, J., R. Owen, and P. Macnaghten, Developing a framework for responsible innovation. Research Policy, 2013. 42(9): p. 1568-1580. 